Türk Turizm Araştırmalari Dergisi
2021, 5(1): $443-458$.
ISSN: $2587-0890$ Dergi web sayfasi: $\underline{\text { https://www.tutad.org }}$

\title{
Kapadokya Bölgesinin Destinasyon Rekabetçiliğinin Paydaşlar Perspektifinden Değerlendirilmesi*
}

Dr. Öğr. Üyesi Mehmet Halit AKIN, Erciyes Üniversitesi, Turizm Fakültesi, Kayseri, e-posta: halitakin@erciyes.edu.tr ORCID: https://orcid.org/0000-0002-9455-0323

Prof. Dr. Kurtuluş KARAMUSTAFA, Erciyes Üniversitesi, Turizm Fakültesi, Kayseri Üniversitesi Rektörlük, Kayseri, e-posta: karamustafa@erciyes.edu.tr

ORCID: https://orcid.org/0000-0002-6581-6276

Prof. Dr. Yüksel ÖZTÜRK, Ankara Hacı Bayram Veli Üniversitesi, Turizm Fakültesi, Ankara, eposta: yuksel.ozturk@hbv.edu.tr ORCID: https://orcid.org/0000-0002-4320-5626

Öz

Teknolojik gelişimlerin uluslararası turizm hareketlerini daha kolay hale getirmesi ve destinasyonlarla ilgili bilgilere kolay ulaşabilme imkânı sunması, destinasyonları bölgesel, ulusal ve uluslararası düzeyde yoğun bir rekabet ortamına çekmektedir. Dolayısıyla destinasyon rekabetçiliğinin değerlendirilmesine yönelik araştırmaların önemi gittikçe artmaktadır. Bu bilgiler ışığında bu araştırmada, Kapadokya Bölgesi örneğinde kültür ağırlıklı tek veya sınırlı sayıda ürüne sahip olan destinasyonların rekabetçiliklerinin birçok farklı paydaş grupları açısından değerlendirilerek ilgili bilgi birikimine özgün katkıların sunulması amaçlanmaktadır. Araştırmanın amacı doğrultusunda, kolayda örneklem tekniğinden faydalanarak 277 anket formu toplanmıştır. Yapılan analizler neticesinde, Kapadokya Bölgesinin bütün faktörlerinin ortalamanın üzerinde değere sahip olduğu ve destinasyon rekabetçiliği bakımından bölgenin güçlü yönlerini oluşturduğu görülmüştür. Buna karşın faktörleri oluşturan alt ifadelerden su, spor, eğlence tesisleri ve faaliyetleri ile ilişkili ifadelerin ise bölgenin geliştirilmesi gereken zayıf yönlerini temsil ettiği saptanmıştır.

* Bu çalışma, "Bir Turistik Destinasyon Olarak Kapadokya Bölgesinin Destinasyon Rekabetçiliği Analizi" başlıklı doktora tezinden ve MTCON-Conference on Managing Tourism Across Continents'de sözlü olarak sunulan "Paydaşlar Perspektifinden Destinasyon Rekabetçiliği: Kapadokya Bölgesi Örneği” başlıklı genişletilmiş özet bildiriden üretilmiştir. Ayrıca, Anatolia: Turizm Araştırmaları Dergisinde 31 (2) yayımlanan "Destinasyon Rekabetçilik Analizi: Kapadokya Bölgesi Örneği" adlı çalışmanın devamı niteliğindedir. Erciyes Üniversitesi Bilimsel Araştırma Projeleri Birimi tarafından SDK-2017-7653 kodlu proje ile desteklenmiştir.

Anahtar Kelimeler: Paydaşlar, Destinasyon Rekabetçiliği, Kapadokya Bölgesi.

Makale Gönderme Tarihi: 20.10.2020

Makale Kabul Tarihi: 08.03.2021

Önerilen Atıf:

Akın, M. H., Karamustafa, K. ve Öztürk, Y. (2021). Kapadokya Bölgesinin Destinasyon Rekabetçiliğinin Paydaşlar Perspektifinden Değerlendirilmesi, Türk Turizm Araştırmaları Dergisi, 5(1): 443-458.

(c) 2021 Türk Turizm Araştırmaları Dergisi. 


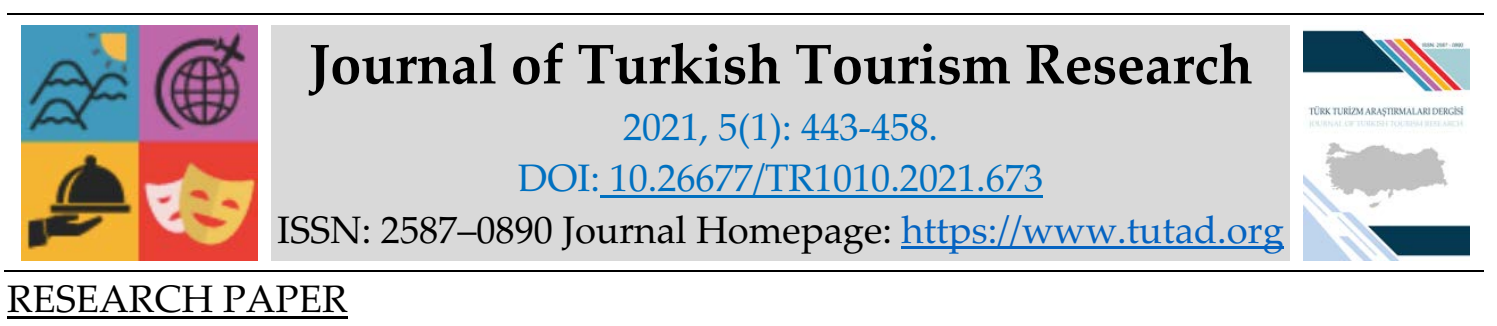

\title{
Evaluation of Destination Competitiveness of the Cappadocia Region from the Stakeholders Perspective
}

Assistant Prof. Dr. Mehmet Halit AKIN, Erciyes University, Faculty of Tourism, Kayseri, e-mail: halitakin@erciyes.edu.tr ORCID: https://orcid.org/0000-0002-9455-0323

Prof. Dr. Kurtuluş KARAMUSTAFA, Erciyes University, Faculty of Tourism, Kayseri University, Rector's Office, Kayseri, e-mail: karamustafa@erciyes.edu.tr ORCID: https://orcid.org/0000-0002-6581-6276

Prof. Dr. Yüksel ÖZTÜRK, Ankara Hacı Bayram Veli University, Faculty of Tourism, Ankara, email: yuksel.ozturk@hbv.edu.tr ORCID: https://orcid.org/0000-0002-4320-5626

\begin{abstract}
The fact that technological developments make international tourism movements easier and faster, also provide the opportunity to access information about destinations more easily attract the destinations to a more intense competitive environment at the regional, national and international levels. Therefore, the importance of research for the evaluation of destination competitiveness is increasing. In this line, this study aims to evaluate the competitiveness of the destinations offering a single product or limited number of products on cultural tourism in terms of many different stakeholders in the case of Cappadocia and to present original contributions to the relevant knowledge. For the purpose of this research, 277 questionnaires were gathered by making use of the sampling technique. As a result of the analysis, it has been observed that all factors of the Cappadocia Region have above average mean values and constitute the strengths of the Region in terms of destination competitiveness. On the other hand, it has been determined that the sub-expressions related to water, sports, recreational facilities and activities represent the weaknesses of the Region needed to be improved.
\end{abstract}

Keywords: Stakeholders, Destination Competitiveness, Cappadocia Region.

Received: 20.10 .2020

Accepted: 08.03.2021

\section{Suggested Citation:}

Akın, M. H., Karamustafa, K. and Öztürk, Y. (2021). Evaluation of Destination Competitiveness of the Cappadocia Region from the Stakeholders Perspective, Journal of Turkish Tourism Research, 5(1): 443-458.

(C) 2021 Türk Turizm Araştırmaları Dergisi. 


\section{GİRIŞ}

Uluslararası turizm hareketlerinde, özellikle İkinci Dünya Savaşı sonrasında ciddi artışlar görülmüş (Bayer, 1992) ve küreselleşme ile teknolojik gelişmeler ülkeler arasındaki sınırları büyük ölçüde kaldırarak ülkelerarasındaki insan, para ve ürün hareketliliğini de ivme kazandırarak artırmıştır (Dahlman, 2007). Bu durum, özellikle uluslararası turizm hareketliliğinde daha fazla pazar payına sahip olmak isteyen destinasyonları ciddi bir rekabet ortamına taşımıştır. Yoğunlaşan rekabet ortamında ise farklılık oluşturarak ön plana çıkmak isteyen destinasyonlar için sahip olunan üstünlük ve zayıf yönlerin belirlenmesi kaçınılmaz olmuştur. Dolayısıyla destinasyon rekabetçilik modellemelerine ve ilgili modeller aracıllı̆ı̆yla destinasyon rekabetçilik analizlerine yönelik araştırmacıların ve uygulayıcıların ilgileri giderek artmıştır (Faulkner vd., 1999; Dwyer, Forsyth ve Rao, 2000; Heath, 2002; Dwyer ve Kim, 2003; Dragićević vd., 2009; Armenski vd., 2011; Hallman vd., 2014; Chin vd., 2017; Reisinger vd., 2018; Gupta ve Singh, 2019; Andrades ve Dimanche, 2019; Kubickova ve Martin, 2020).

Turizm sektörünün yapısının diğer sektörlere göre farklılık göstermesi ve farklı birçok bileşeni kapsıyor olması (Bitner ve Booms, 1982), turizm sektöründe rekabetçiliğin farklı birçok değişkenle bağlantılı ve ilişkili olduğunu göstermektedir. Bu noktada, turizm sektörünün merkezi bir bileşeni ve önemli bir turistik ürünü olarak nitelendirilen (Scorțe vd., 2013) ve küresel rekabet ortamındaki pozisyonunu belirleyen destinasyonların (Meng, 2006) rekabetçilikleri ön plana çıkmaktadır. Bu nedenledir $\mathrm{ki}$ araştırmacıların ve uygulayıcıların destinasyon rekabetçiliğine yönelik ilgisi giderek artmaktadır. Diğer bir ifadeyle turizm sektörü bakımından destinasyonların ulusal ve uluslararası düzeyde sahip olduğu önemin yanı sıra turist tercihlerini etkileyen bir çekim özelliği taşıması destinasyon rekabetçiliğine verilen önemi ve ilgiyi daha da artmaktadir.

Destinasyon rekabetçiliği ile ilgili çalışmalar incelendiğinde (Faulkner vd., 1999; Heath, 2002; Dragićević vd., 2009; Hallman vd., 2014; Reisinger vd., 2018; Andrades ve Dimanche, 2019; Gupta ve Singh, 2019), çalışmaların genel olarak deniz-kum-güneş gibi daha yaygın kullanılan ancak rekabet gücü daha zayıf olan ürünlere sahip destinasyonların analiz edilmesine yönelik gerçekleştirildiği görülmektedir. Ayrıca kültür odaklı destinasyonlar kapsamındaki araştırmaların ise oldukça fazla ürün çeşitliliği bulunan destinasyonlara yönelik gerçekleştirildiği anlaşılmaktadır. Kapadokya gibi kültür odaklı veya daha sınırlı sayıda ürüne sahip olan destinasyonlara yönelik rekabetçilik araştırmalarının daha sınırlı düzeyde olduğu anlaşılmaktadır. Diğer taraftan, ilgili literatürde yer alan ve destinasyon rekabetçiliğini paydaşlar açısından değerlendiren araştırmalar incelendiğinde de (Armenski vd., 2011; Goffi ve Cucculelli 2012; Hallman vd., 2012, Bakhshinejad 2014; Hallman vd., 2014; Zhou vd., 2015; Yüzbaşığlu vd., 2016; Armenski vd., 2017; Nkinda vd., 2018; Luštıcký ve Musil, 2019), bu araştırmaların genel olarak birçok farklı paydaş grupları kapsamında konuyu ele almaktan ziyade daha dar kapsamlı paydaş grubu veya grupları kapsamında değerlendirmeler yaptığı görülmektedir. Dolayısıyla bu çalışmada, birçok farklı paydaş açısından kültür ağırlıklı tek veya sınırlı düzeyde turistik ürün sunan Kapadokya Bölgesinin destinasyon rekabetçilik analizinin yapılmasıyla ilgili bilgi birikimine daha güncel ve kapsamlı katkıların sunulması amaçlanmaktadır.

\section{KAVRAMSAL ÇERÇEVE}

Destinasyon rekabetçiliğine değinmeden önce rekabetçilik kavramını tanımlamak faydalı olacaktır (García Sánchez ve Siles López, 2015). Rekabetçilik kavramı, genel olarak sektör ve ülke düzeylerinde ele alınarak incelenmektedir (Aktan ve Vural, 2004: 107). Ülke düzeyinde rekabetçilik, bir ülkenin ekonomik büyümesinin yanı sıra ekonomik, politik ve stratejiler 
bakımından sağladığı başarıyı ifade ederken (Dwyer ve Kim, 2003) sektör düzeyinde rekabetçilik ise işletmelerin rakiplerine kıyasla farklılıklar elde etmesini sağlayan çekicilikler ve nitelikler ile işletme performansını ifade etmektedir (Porter, 1980; García Sánchez ve Siles López, 2015).

Turizm sektörü açısından rekabetçilik kavramının tanımlanması, geleneksel ürünlerin üretimi ile turistik ürünlerin üretimi arasındaki farklılıklardan dolayı önem arz etmektedir (Bahar ve Kozak, 2012: 41). Bu bağlamda, d'Hauteserre (2000), turizmde rekabetçilik kavramını sektörün bulunduğu rekabet ortamında rakiplerine karşı pazar payını koruyacak ve sürekli geliştirecek değer sağlayan ürünlerin geliştirilme yeteneği olarak ifade etmektedir. Dwyer ve Kim (2003) ise turistik rekabetçilik kavramını potansiyel müşterilere sunulan temel çekiciliklerin ve turist deneyimlerinin, rakiplere kıyasla nitelik bakımından daha üstün olmasının sağlanması olarak değerlendirmektedir.

Destinasyon rekabetçiliği kavramı ise karmaşık bir kavramdır ve genel anlamda kabul görmüş bir tanımı bulunmamaktadır (Crouch ve Ritchie,1999). Bu durum destinasyon rekabetçiliğinin tanımlamasına yansımış ve ilgili literatürde destinasyon rekabetçiliğinin birçok tanımı yer almıştır (Buhalis, 2000; Ritchie ve Crouch, 2003; Dwyer ve Kim, 2003; Enright ve Newton, 2004; Mangion vd., 2005; Tsai vd., 2009; Croes, 2011; Crouch, 2011; Dupeyras ve MacCallum, 2013; Pansiri, 2014; Hanafiah ve Zulkifly, 2018; Reisinger vd., 2018; Gu vd., 2019; Nadalipour vd., 2019). Ritchie ve Crouch (2003)'a göre destinasyon rekabetçiliği, destinasyondaki yerel halkın refahını artırma ve destinasyonun doğal sermayesini koruyarak gelecek nesillere aktarmanın yanı sıra turizm harcamalarını artırma, turist memnuniyetini sağlama ve eşsiz deneyimler sunarak turistleri destinasyona çekme yeteneğidir. Dupeyras ve MacCallum (2013)'da benzer unsurlara odaklanarak destinasyon rekabetçiliğini turistlere kaliteli, yenilikçi ve cazip turistik ürünleri sunma, yerel halk ve turistler için çekicilik unsurları oluşturma, sürdürülebilirlik temelinde sahip olunan kaynakların kullanımını sağlama ve ulusal ve uluslararası piyasada pazar payını artırma yeteneği olarak tanımlamaktadır.

Destinasyon rekabetçiliğinin tanımlanmasına odaklanan araştırmacılar (Porter, 1990; Crouch ve Ritchie, 1999; Hassan, 2000; Dwyer ve Kim, 2003; Gooroochurn ve Sugiyarto, 2005; Ferreira ve Estevao, 2009; Khin vd., 2014; Nadalipour vd., 2019), aynı zamanda destinasyon rekabetçiliğini etkileyen temel göstergeleri belirlemeye yönelik modeller geliştirmeye odaklanmışlardır (AbreuNovais, 2016). Porter (1990), devlet ve şans faktörlerini dış faktör olarak nitelendirdiği Elmas Modelinde, destinasyon rekabetçiliğinin göstergeleri olarak faktör koşulları, talep koşulları, firma stratejisi, yapı ve rekabet, ilgili ve destek sektörler faktörlerini sıralamıştır. Dwyer ve Kim (2003) Bütünleştirilmiş Rekabet Modeli'nde, destinasyon rekabetçiliği göstergelerini daimî kaynaklar, yapay kaynaklar, destek kaynaklar, destinasyon yönetimi, durumsal koşullar ve talep koşulları olmak üzere altı kategori altında toplamıştır. Ferreira ve Estevao (2009) Turizm Kümelenmesinin Bölgesel Rekabetçiliği Modeli'nde, Elmas Modelinde yer alan faktör koşulları, talep koşulları, firma stratejisi, yapı ve rekabet, ilgili ve destek sektörler faktörleri üzerinde geliştirmeler yaparak destinasyon rekabetçiliğini etkileyen dış faktörleri, kaynaklar ve çekicilikler, destinasyon yönetimi, devlet politikaları ve üniversiteler olarak sıralamıştır. Destinasyon rekabetçiliğinin sürdürülebilirliğe odaklanan Nadalipour vd., (2019) ise Bütünleştirilmiş Sürdürülebilir Destinasyon Rekabetçiliği Modeli'nde, destinasyon rekabetçiliğini ekonomik, sosyo-kültürel, çevresel rekabetçiliğin yanı sıra sürdürülebilir politika oluşturma ve yönetimi ile turist memnuniyeti ve davranışları üzerine konumlandırmıştır.

Diğer taraftan Hassan (2000)'in çevresel sürdürülebilirlik üzerinde konumlandırdığı destinasyon rekabetçiliğini, Crouch ve Ritchie (1999), kaynak varlığı ve yönetimi temelinde destinasyonların karşılaştırmalı ve rekabetçi avantajlarına odaklanmıştır. Gooroochurn ve Sugiyarto (2005) destinasyon rekabetçiliğinde, turizm rekabetçiliğinin izlenilmesine odaklanmış ve fiyat, çevre, teknoloji, insan kaynakları, sosyal, altyapı gibi göstergelerin rekabetçilik bakımından izlenmesi 
ve değerlendirilmesi gereken hususlar olduğunu belirtmiştir. Khin vd., (2015) ise destinasyon rekabetçiliğini destinasyonların niteliklerine konumlandırmıştır. Bu kapsamda, çekicilikler, genel altyapı, destinasyon imajı, destinasyon yönetimi, talep koşulları, turizm üstyapı gibi göstergelerin destinasyon rekabetçiliğine temel oluşturduğunu ve bu niteliklerin destinasyon rekabetçiliğini etkilediğini ifade etmiştir.

Destinasyon rekabetçiliği ile ilgili geliştirilmiş olan modeller incelendiğinde, ilgili modellerin genel olarak eski modelleri temel alarak eksiklikleri ortadan kaldırmaya ve geliştirmeye odaklandıkları görülmektedir. Bununla birlikte modellerin sunulduğu araştırmalarda, rekabetçilik analizinin yapılması ve rekabetçi pozisyonun belirlenmesinin destinasyonların rekabetçilik bakımından sahip olduğu göstergelerin üzerine konumlandırıldığı görülmektedir. $\mathrm{Bu}$ doğrultuda destinasyon rekabetçiliğinin belirleyicileri olarak ortaya konan göstergeler bütüncül bir yaklaşımla incelendiğinde, önemli bir çekicilik unsuru olan destinasyonun sahip olduğu kaynakların yanı sıra destinasyon yönetimi, devlet politikaları, turist algılamaları ve motivasyon faktörleri, destekleyici altyapılar, emniyet, güvenlik, konum, imaj, sürdürülebilirlik gibi unsurların ön plana çıktığı görülmektedir.

\section{YÖNTEM}

Kapadokya Bölgesinin destinasyon rekabetçiliği bakımından sahip olduğu üstün ve zayıf yönlerinin belirlenmesi doğrultusunda ilgili literatüre birtakım bilgi birikiminin ve önerilerin sunulmasını amaçlayan bu araştırma, konuyla ilgili bir ölçek aracılığıyla verilerin toplanarak analiz edilmesi ve değerlendirilmesine dayalıdır. Araştırmanın amacı doğrultusunda, verilerin toplanması için Dwyer ve Kim (2003) tarafından geliştirilen ve altı faktörden oluşan 'Bütünleştirilmiş Rekabet Modeli' ölçeğinden yararlanılmıştır. Ölçek içerisinde, hem araştırmanın amacına hem de evrenine uygun olması amacıyla birtakım değişiklikler yapılmıştır. Örneğin, Kapadokya Bölgesi ile ilişkili olmayan ulusal turizm örgütü, casino gibi ifadeler çıkarılmış, alışveriş imkânlarının çeşitliliği/kalitesi gibi ifadeler ayrıştırılarak iki farklı ifade olarak konulmuş ve bazı ifadeler ise Dwyer ve Kim'in (2003) ölçekle birlikte sunmuş oldukları 'Destinasyon Rekabetçiliğinin Seçilmiş Göstergeleri' temel alınarak eklenmiştir. Demografik özellikler hariç olmak üzere, ölçekte toplam 62 ifade yer almış, 5'li Likert tipi ölçekten yararlanılmış ve ‘ $0=$ bilmiyorum / emin değilim' seçeneği eklenmiştir.

Yukarıda bahsedilen unsurlar dâhilinde hazırlanan anket formunun geçerliliğinin sağlanması için birtakım süreçler izlenmiştir. Öncelikli olarak, ölçeğin geçerliliğinde birincil unsur olarak kabul edilen (Karasar, 2014) Cronbach's Alfa katsayısı hesaplanmış $(\alpha=0,945)$ ve güvenirlik katsayısının kabul edilebilir düzeyde olduğu görülmüştür (Bajpai ve Bajpai, 2014). Daha sonra ölçeğin kapsam geçerliliğinin sağlanması için 31 katılımcı üzerinde pilot test uygulaması yapılmış, yanıtlama sürecinde katılımcıların ifadeleri anlama bakımından sorun yaşamadığı ve yanıtlamamaya yönelik bir eğilimlerinin olmadığı gözlemlenmiştir. Son olarak bahsedilen geçerlilik ve güvenirlikle ilgili süreçleri desteklemek için konuyla ilgili uzman iki akademisyenin görüşleri alınarak gerekli değerlendirme ve düzenlemeler yapılmıştır.

Araştırma kapsamında uygulama alanı olarak belirlenen Kapadokya Bölgesinde faaliyet gösteren paydaşların niceliksel olarak değerleri, sektörün mevsimsellik özelliği ve işletmelerin yapısal farklılıklarından dolayı tam olarak tespit edilememiştir. Kapadokya Bölgesinde faaliyet gösteren turizm paydaşlarının sayısının yaklaşık değeri 1005 olarak hesaplanmıştır. Bütün paydaşlara ulaşmanın oluşturacağı zaman ve bütçe yetersizliğini önlemek adına örneklem belirlemesine gidilmiştir. Araştırmanın amacına uygun olduğu düşünülen olasılığa dayalı olmayan örneklemelerden kolayda örneklem araştırmanın örneklem türü olarak seçilmiştir. Araştırmanın örneklemi, \%95 güven düzeyinde $\% 5$ hata payıla 278 olarak hesaplanmıştır 
(https://www.surveysystem.com). Katılımclların hepsinin dâhil olduğu paydaş grubunu temsil edecek kişiler olmaları kaydıyla 12-27 Temmuz 2019 tarihlerinde, bölgedeki konaklama, seyahat, yeme-içme işletmelerinde ve kamu kurumlarında yüz yüze ve bırak-topla yöntemlerinin yanı sıra online soru formu aracılığıyla uygulanmıştır. Toplamda 299 soru formu yanıtlanmış ve analize uygun olan 277 soru formu analizlere dâhil edilmiştir. Bu durum, araştırmanın sınırlılığını oluşturmaktadır.

Tablo 1. Araştırmanın Evreni

\begin{tabular}{|c|c|c|c|}
\hline Paydaş Grupları & Paydaş Türü & Sinıfi & $\begin{array}{l}\text { Evren } \\
\text { Sayis1 }\end{array}$ \\
\hline \multirow{4}{*}{$\begin{array}{l}\text { İşletme sahipleri, } \\
\text { yöneticileri ve çalışanları }\end{array}$} & \multirow{2}{*}{$\begin{array}{l}\text { Konaklama } \\
\text { işletmeleri }\end{array}$} & Bakanlıktan belgeli & 112 \\
\hline & & $\begin{array}{l}\text { Yerel yönetimlerden } \\
\text { belgeli }\end{array}$ & 355 \\
\hline & Seyahat işletmeleri & - & 195 \\
\hline & $\begin{array}{l}\text { Yeme-içme } \\
\text { işletmeleri }\end{array}$ & - & 250 \\
\hline \multirow{3}{*}{$\begin{array}{l}\text { Turizm eğitimi veren } \\
\text { kurumların temsilcileri }\end{array}$} & \multirow{3}{*}{ Eğitim Kurumları } & Kurum temsilcisi & 7 \\
\hline & & Turizm akademisyeni & 62 \\
\hline & & Lisansüstü öğrenci & 3 \\
\hline $\begin{array}{l}\text { Turizmle ilgili kamu } \\
\text { kurumu temsilcileri }\end{array}$ & - & - & 5 \\
\hline $\begin{array}{l}\text { Turizmle ilgili sivil toplum } \\
\text { kuruluşu temsilcileri }\end{array}$ & - & - & 13 \\
\hline Yerel yönetim temsilcileri & - & - & 3 \\
\hline \multicolumn{3}{|l|}{ TOPLAM } & $\sim 1005$ \\
\hline
\end{tabular}

Kaynak: Araştırmacılar tarafından elde edinilen verilere göre derlenmiştir.

\section{BULGULAR}

İlgili literatürlerle benzer şekilde (Chen vd., 2008; Vujko vd., 2016; Yüzbaşığlu vd., 2016; Reisinger vd., 2018; Akın vd., 2020), Kapadokya Bölgesinin destinasyon rekabetçiliği bakımından sahip olduğu üstün ve zayıf yönlerin belirlenmesinde frekans analizlerinden yararlanılmıştır. Bu kapsamda, bütün ifadelerin ortalama ve standart sapma değerleri hesaplanmıştır. Katılımcıların demografik özellikleri ile kurumsal faktörlerine yönelik ise yüzde hesaplamalarından faydalanılmıştır.

Tablo 2 incelendiğinde, katılımcıların genel çoğunluğunu 31-40 yaş aralığında (\%47,6), erkek $(\% 64,3)$, evli $(\% 64,6)$, ön lisans ve lisans düzeyinde (\%44,8) eğitime sahip olan ve 4.000 TL ve altı $(\% 40,4)$ gelire sahip olan katılımcıların oluşturduğu görülmektedir. Katılımcıların genel çoğunluğunu belli bir eğitim düzeyine sahip katılımcılar oluşturuyor olmasına karşın turizm eğitimi alan katılımcıların oranının (\%48,7) kısmen düşük olduğu görülmektedir. 
Tablo 2. Paydaşların Demografik Özelliklerinin Dağılımları

\begin{tabular}{|c|c|c|c|}
\hline Demografik Özellikler & Gruplar & $\mathrm{f}$ & $\%$ \\
\hline \multirow{4}{*}{ Yaş } & 30 yaş ve altı & 50 & 18,1 \\
\hline & $31-40$ & 132 & 47,6 \\
\hline & $41-50$ & 67 & 24,2 \\
\hline & 51 yaş ve üzeri & 28 & 10,1 \\
\hline \multirow{2}{*}{ Cinsiyet } & Erkek & 178 & 64,3 \\
\hline & Kadın & 99 & 35,7 \\
\hline \multirow{2}{*}{ Medeni durum } & Bekâr & 98 & 35,4 \\
\hline & Evli & 179 & 64,6 \\
\hline \multirow{3}{*}{ Eğitim durumu } & İlk ve orta öğretim & 90 & 32,5 \\
\hline & Ön lisans ve lisans & 124 & 44,8 \\
\hline & Lisansüstü & 63 & 22,7 \\
\hline \multirow{2}{*}{ Turizm eğitimi alma durumu } & Evet & 135 & 48,7 \\
\hline & Hayır & 142 & 51,3 \\
\hline \multirow{5}{*}{ Aylık ortalama gelir } & 4.000 TL ve alt1 & 112 & 40,4 \\
\hline & $4.001-6.000 \mathrm{TL}$ & 91 & 32,9 \\
\hline & $6.001-8.000 \mathrm{TL}$ & 38 & 13,7 \\
\hline & 8.001 TL ve üzeri & 36 & 13 \\
\hline & TOPLAM & 277 & 100 \\
\hline
\end{tabular}

Tablo 3. Paydaşların Kurumsal Faktörlerine İlişkin İstatistikler

\begin{tabular}{|c|c|c|c|}
\hline Kurumsal Faktörler & Gruplar & f & $\%$ \\
\hline \multirow{4}{*}{ İşletme veya kurum türü } & Konaklama işletmesi & 102 & 36,8 \\
\hline & Seyahat acentesi & 67 & 24,2 \\
\hline & Yiyecek içecek işletmesi & 63 & 22,8 \\
\hline & Kamu kurumu & 45 & 16,2 \\
\hline \multirow{4}{*}{$\begin{array}{l}\text { İşletme veya kurumdaki } \\
\text { görevi }\end{array}$} & $\begin{array}{l}\text { İşletme sahibi veya üst düzey } \\
\text { yönetici }\end{array}$ & 130 & 46,9 \\
\hline & $\begin{array}{l}\text { Devlet memuru, turizm } \\
\text { akademisyeni veya lisansüstü } \\
\text { öğrencisi }\end{array}$ & 43 & 15,5 \\
\hline & Diğer* & 104 & 37,6 \\
\hline & TOPLAM & 277 & 100 \\
\hline
\end{tabular}

*Yönetici statüsü dışındaki ön büro görevlisi, garson, satış temsilcisi gibi katılımcılar

Tablo 3'de verilen kurumsal faktörlere ilişkin dağılımlarda, işletme veya kurum türünde genel çoğunluğu konaklama işletmelerinin $(\% 36,8)$, işletme veya kurumdaki görevinde ise işletme sahibi veya üst düzey yöneticilerinin $(\% 46,9)$ oluşturduğu görülmektedir.

Katılımcıların daimî kaynaklara yönelik ortalama değerlerinin yer aldığı Tablo 4 incelendiğinde, bütün ifadelerin ortalamanın üzerinde değere sahip olduğu ve özellikle doğal güzellikler, zengin kültürel alanlar gibi ifadelerin yüksek değerlere sahip oldukları görülmektedir. Dolayısıyla bölgenin daimî kaynakları, bölgenin destinasyon rekabetçiliği bakımından sahip olduğu güçlü yönleri içermektedir. 
Tablo 4. Katılımcıların Daimî Kaynaklara Yönelik Ortalama ve Standart Sapma Değerleri

\begin{tabular}{clcc}
\hline No & İfadeler & $\overline{\mathbf{x}}$ & S.S. \\
\hline $\mathbf{1 .}$ & İklimi & 3,43 & 1,01 \\
\hline 2. & Destinasyonun hijyenikliği & 3,25 & 1,19 \\
\hline 3. & Doğal güzellikleri (peri bacası, yeraltı şehri gibi) & 4,58 & 0,78 \\
\hline 4. & Bozulmamış doğası & 3,46 & 1,18 \\
\hline $\mathbf{5 .}$ & Flora ve faunası (bitki ve hayvan türleri) & 2,66 & 1,37 \\
\hline 6. & Milli parkları & 3,72 & 1,36 \\
\hline 7. & Zengin sanatsal ve mimari özellikleri & 3,91 & 1,12 \\
\hline 8. & Zengin geleneksel sanatları (çömlekçilik, seramik, oymacılık gibi) & 4,18 & 0,97 \\
\hline 9. & Mutfak (yemek) çeşitliliği & 3,05 & 1,29 \\
\hline 10. & Zengin kültürel alanları (müzeleri, tarihi yerleri ve sit alanları gibi) & 4,16 & 1,10 \\
\hline GENEL ORTALAMA & 3,64 & \\
\hline & &
\end{tabular}

Tablo 5. Katılımcıların Yapay Kaynaklara Yönelik Ortalama ve Standart Sapma Değerleri

\begin{tabular}{|c|c|c|c|}
\hline No & İfadeler & $\overline{\mathbf{x}}$ & S.S. \\
\hline 1. & Su aktiviteleri (yüzme, sörf, tekne gezisi gibi) & 1,79 & 1,39 \\
\hline 2. & $\begin{array}{l}\text { Doğa aktiviteleri (doğa yürüyüşü, kamp alanları, kuş } \\
\text { gözlemciliği vb.) }\end{array}$ & 3,63 & 1,26 \\
\hline 3. & Macera aktiviteleri (balon, rafting, paraşüt vb.) & 3,96 & 1,32 \\
\hline 4. & Eğlence parkları/tema parkları & 2,21 & 1,45 \\
\hline 5. & Eğlence hizmetlerinin (gece hayatı, tiyatro, sinema vb.) kalitesi & 2,45 & 1,54 \\
\hline 6. & $\begin{array}{l}\text { Eğlence hizmetlerinin (gece hayatı, tiyatro, sinema vb.) } \\
\text { çeşitliliği }\end{array}$ & 2,51 & 1,56 \\
\hline 7. & Festivallerin/özel etkinliklerin çeşitliliği & 2,67 & 1,32 \\
\hline 8. & Konaklama tesislerinin kalitesi & 3,77 & 1,11 \\
\hline 9. & Konaklama tesislerinin çeşitliliğ & 4,01 & 1,01 \\
\hline 10. & Havalananında sunulan hizmetlerin kalitesi & 2,68 & 1,47 \\
\hline 11. & Turist rehberliği ve danışma hizmetlerinin yeterliliği & 3,37 & 1,17 \\
\hline 12. & Yerel turizm ulaşım sistemlerinin yeterliliği & 3,11 & 1,14 \\
\hline 13. & Yerel turizm ulaşım sistemlerinin kalitesi & 3,03 & 1,23 \\
\hline 14. & Turistlerin doğal alanlara erişebilirlikleri & 3,28 & 1,21 \\
\hline 15. & Toplantı (kongre) tesislerinin kalitesi & 2,89 & 1,51 \\
\hline 16. & Yiyecek ve içecek işletmelerinin kalitesi & 3,15 & 1,28 \\
\hline 17. & Boş zaman değerlendirme aktivitelerinin çeşitliliği & 2,88 & 1,30 \\
\hline 18. & Spor faaliyetlerinin (golf, tenis, futbol tesisleri vb.) çeşitliliği & 2,16 & 1,29 \\
\hline 19. & Alışveriş imkânlarının çeşitliliği & 3,18 & 3,46 \\
\hline 20. & Alışveriş tesislerinde sunulan ürünlerin kalitesi & 3,08 & 1,30 \\
\hline 21. & $\begin{array}{l}\text { Turistlere alışveriş ürünlerine harcadıkları paranın karşılığının } \\
\text { verilmesi düzeyi }\end{array}$ & 3,23 & 1,46 \\
\hline \multicolumn{2}{|c|}{ GENEL ORTALAMA } & 3,01 & \\
\hline
\end{tabular}

Bölgenin yapay kaynaklarına yönelik katılımcıların ortalama değerlerine göre, su aktiviteleri, spor faaliyetleri, eğlence parkları/tema parkları gibi ifadeler ortalamanın altında değere sahip olan bölgenin zayıf yönlerini oluşturmaktadır. Diğer ifadelerin ortalamaları ile genel ortalama ise 
genel olarak yüksek düzeydedir. Ortalamanın üzerinde değere sahip olan konaklama tesisleri, macera aktiviteleri gibi ifadeler, bölgenin rekabetçiliğinde güçlü yönleri teşkil etmektedirler.

Tablo 6. Katılımcıların Destek Kaynaklara Yönelik Ortalama ve Standart Sapma Değerleri

\begin{tabular}{clcc}
\hline No & Iffadeler & $\overline{\mathbf{X}}$ & $\mathbf{S . S .}$ \\
\hline $\mathbf{1 .}$ & Turistlere yönelik să̆llk hizmetlerinin yeterliliği & 2,95 & 1,51 \\
\hline 2. & Banka ve döviz bürolarının yeterliliği & 3,18 & 1,46 \\
\hline 3. & Turistlere yönelik iletişim sistemlerinin yeterliliği & 3,11 & 1,46 \\
\hline 4. & Destinasyonun ulaşım olanaklarının (seferlerinin) sıklı̆̆ 1 & 2,85 & 1,21 \\
\hline 5. & Turizm altyapısının turist ihtiyaçlarını karşılayabilme yeterliliği & 3,10 & 1,28 \\
\hline 6. & Destinasyonun diğer destinasyonlara olan uzaklığı/uçuş süreleri & 2,70 & 1,41 \\
\hline 7. & Destinasyona olan uçuş sayılarının yeterliliği & 2,31 & 1,41 \\
\hline 8. & Turist güvenliği ve emniyetinin yeterliliği & 3,52 & 1,44 \\
\hline 9. & Türkiye'deki gümrük bürolarının yeterliliği & 2,02 & 1,64 \\
\hline 10. & Türkiye'deki gümrük bürosu görevlilerinin tutum/tavırları & 1,87 & 1,60 \\
\hline 11. & Vize maliyetlerinin yüksekliği & 2,12 & 1,67 \\
\hline 12. & Vize ile ilgili yasal işlemlerin çokluğu & 2,30 & 1,76 \\
\hline 13. & Yerel halkın turistlere yönelik cana yakınlık derecesi & 3,60 & 1,31 \\
\hline GENEL ORTALAMA & 2,74 & \\
\hline & &
\end{tabular}

Tablo 6'ya göre, Kapadokya Bölgesi destek kaynaklar bakımından ortalamanın kısmen üzerinde bir genel ortalamaya sahip olmasına karşın destek kaynaklar içerisinde hem güçlü hem de zayıf yönlere sahiptir. Turist güvenliği ve emniyeti, yerel halkın turistlere yönelik cana yakınlık derecesi gibi ifadeler güçlü yönleri; vize ve gümrükle ilgili ifadeler ise zayıf yönleri oluşturmaktadır.

Tablo 7. Katılımcıların Destinasyon Yönetimi Yönelik Ortalama ve Standart Sapma Değerleri

\begin{tabular}{clcc}
\hline No & İfadeler & $\overline{\mathbf{x}}$ & $\mathbf{S . S .}$ \\
\hline $\mathbf{1 .}$ & Destinasyonun olumlu imaj düzeyi & 3,63 & 1,33 \\
\hline 2. & $\begin{array}{l}\text { Destinasyon deneyimlerinin etkin bir paket halinde sunulma } \\
\text { düzeyi }\end{array}$ & 3,08 & 1,36 \\
\hline 3. & $\begin{array}{l}\text { Turizm çalışanlarının değişen turistlerin ihtiyaçlarına cevap } \\
\text { verebilme yetenekleri }\end{array}$ & 3,21 & 1,17 \\
\hline 4. & $\begin{array}{l}\text { Destinasyon ürünleri ile turist tercihleri arasındaki uyumluluk } \\
\text { düzeyi }\end{array}$ & 3,21 & 1,24 \\
\hline 5. & Kamu çalışanlarının turizm alanındaki eğitim düzeyleri & 2,37 & 1,30 \\
\hline 6. & Özel sektör çalışanlarının turizm alanındaki eğitim düzeyleri & 2,70 & 1,19 \\
\hline 7. & $\begin{array}{l}\text { Destinasyondaki sektörel geliş̧imin turistlerin ihtiyaçlarına cevap } \\
\text { verebilme düzeyi }\end{array}$ & 2,98 & 1,13 \\
\hline 8. & $\begin{array}{l}\text { Turizm işletmelerinin değişen turistlerin ihtiyaçlarına cevap } \\
\text { verebilme yetenekleri }\end{array}$ & 3,10 & 1,19 \\
\hline GENEL ORTALAMA & 3,03 & \\
\hline
\end{tabular}

Destinasyon yönetimi faktörüne ilişkin değerler, genel ortalamanın üzerinde yer almaktadır. Dolayısıyla 'kamu çalışanlarının turizm alanındaki eğitim düzeyleri' alt ifadesi haricinde diğer 
bütün alt ifadeleriyle birlikte destinasyon yönetimi faktörü, Kapadokya Bölgesinin rekabetçilik bakımından güçlü yönlerini teşkil etmektedir.

Tablo 8. Katılımcıların Durumsal Koşullara Yönelik Ortalama ve Standart Sapma Değerleri

\begin{tabular}{llcc}
\hline No & İfadeler & $\overline{\mathbf{x}}$ & S.S. \\
\hline \multirow{2}{*}{ 1. } & $\begin{array}{l}\text { Destinasyonun sahip olduğu egzotikliğin (ilginç çekiciliklerin) } \\
\text { yeterliliği }\end{array}$ & 3,80 & 1,37 \\
\hline 2. & Turist gönderen pazarlardan destinasyona olan uçuşların fiyatı & 2,50 & 1,55 \\
\hline 3. & Destinasyona yönelik hazırlanmış olan paket turların fiyatı & 2,50 & 1,49 \\
\hline 4. & Rakiplere kıyasla Kapadokya Bölgesinde yapılan tatilin fiyatı & 2,79 & 1,44 \\
\hline 5. & $\begin{array}{l}\text { Turistlere konaklamak için harcadıkları paranın karşılığının } \\
\text { verilme düzeyi }\end{array}$ & 3,42 & 1,43 \\
\hline 6. & $\begin{array}{l}\text { Destinasyondaki döviz kuru hareketlerinin turistlerin seyahat } \\
\text { kararlarına etki düzeyi }\end{array}$ & 3,00 & 1,60 \\
\hline 7. & Destinasyonda turistlere yönelik işlenen suçların görülme sıklı̆̆ı & 2,16 & 3,61 \\
\hline 8. & $\begin{array}{l}\text { Turistlere turizm deneyimlerine harcadıkları paranın karşılığının } \\
\text { verilmesi düzeyi }\end{array}$ & 3,22 & 1,37 \\
\hline GENEL ORTALAMA & 2,92 & \\
\hline
\end{tabular}

Tablo 8'e göre, ilginç çekicilikler, fiyatlar gibi alt ifadeleri kapsayan durumsal koşullar faktörü, bölgenin destinasyon rekabetçiliği bakımından güçlü yönlerini teşkil etmektedir.

Tablo 9. Katılımcıların Talep Koşullarına Yönelik Ortalama ve Standart Sapma Değerleri

\begin{tabular}{clcc}
\hline No & \multicolumn{1}{c}{ İfadeler } & $\overline{\mathbf{x}}$ & S.S. \\
\hline 1. & $\begin{array}{l}\text { Bir bütün olarak Kapadokya Bölgesinin uluslararası bilinirlik } \\
\text { düzeyi }\end{array}$ & 3,52 & 1,35 \\
\hline 2. & $\begin{array}{l}\text { Destinasyonun çekicilik unsurlarının uluslararası bilinirlik } \\
\text { düzeyi }\end{array}$ & 3,40 & 1,35 \\
\hline GENEL ORTALAMA & 3,46 & \\
\hline
\end{tabular}

Talep koşullarına yönelik değerler ise her iki ifadenin de bölgenin rekabetçilik bakımından sahip olduğu güçlü yönleri oluşturduğunu göstermektedir.

Katılımcların bütün ifadelere yönelik ortalama değerlerinin bir bütün olarak değerlendirilmesi, Kapadokya Bölgesinin genel anlamda destinasyon rekabetçiliği bakımından sahip olduğu güçlü ve zayıf yönlerin ortaya konması açısından önemlidir. Buna göre, katılımcıların en yüksek rekabet gücü algılamalarına sahip olduğu ifadeler; doğal güzellikleri $(\bar{x}=4,58)$, zengin kültürel alanları $(\bar{x}=4,16)$, konaklama tesislerinin çeşitliliği $(\bar{x}=4,01)$, zengin sanatsal ve mimari özellikleri $(\bar{x}=3,91)$, destinasyonun sahip olduğu egzotikliğin (ilginç çekiciliklerin) yeterliliği $(\bar{x}=3,80)$, destinasyonun olumlu imaj düzeyi $(\bar{x}=3,63)$ ve turist güvenliği ve emniyetinin yeterliliği $(\bar{x}=3,52)$ olarak sıralanabilir. Katılımcıların en düşük rekabet gücü algılamalarına sahip olduğu ifadeler ise kamu çalışanlarının turizm alanındaki eğitim düzeyleri $(\bar{x}=2,37)$, spor faaliyetlerinin çeşitliliği $(\bar{x}=2,16)$, Türkiye'deki gümrük bürolarının yeterliliği $(\bar{x}=2,02)$, Türkiye'deki gümrük bürosu görevlilerinin tutum/tavırları $(\bar{x}=1,87)$ ve su aktiviteleri $(\bar{x}=1,79)$ olarak sıralanabilir. 


\section{TARTIŞMA}

Paydaşlardan elde edilen verilere dayalı olarak Kapadokya Bölgesinin destinasyon rekabetçiliğinin analiz edilmesi temeline konumlandırılan bu araştırma ile ilgili literatürün yanı sıra sektör temsilcilerine yönelik birçok yaygın etkinin ve özgün katkıların sunulması beklenmektedir. Diğer bir ifadeyle teorik olarak destinasyon rekabetçiliği ile ilgili bilgi birikimine, pratik olarak Kapadokya Bölgesinin destinasyon unsurlarının ve dolaylı olarak ulusal turizmin geliştirilmesine yönelik yaygın etkinin ve özgün katkıların sunulması beklenmektedir. Dolayısıyla araştırma kapsamında elde edilen bulguların değerlendirilmesi ve önerilerin sunulması önem arz etmektedir.

Kurumsal faktörlere ilişkin dağılımlara göre, katılımcıların genel çoğunluğu konaklama işletmesi ve işletme sahibi veya üst düzey yöneticisi gruplarında yer almaktadır. Bölgedeki işletmelerin genel çoğunluğu, yerel veya aile işletmesi olarak faaliyet sürdürmekte ve bu işletmelerin birçoğu konaklama işletmesi olarak faaliyet sürdürmektedir. Ayrıca bu durum, yerel veya aile işletmesi olarak faaliyet gösteren işletmelerde işletme sahibi veya yöneticisine ulaşabilme imkânı sağlamıştır. Sonuç olarak bahsedilen durumlar, katılımcılarda genel çoğunluğun konaklama işletmesi ve işletme sahibi veya üst düzey yöneticisi olmasını sağlamıştır.

Faktörlere yönelik ortalama değerler incelendiğinde, daimî kaynaklar faktörünü oluşturan doğal güzellikler, zengin kültürel alanları, zengin sanatsal çekicilikler gibi alt ifadelerin yüksek ortalama değerine sahip olması, bölgenin önemli bir kültür turizmi destinasyonu olmasının yanı sıra sahip olduğu tarihi, kültürel ve doğal çekicilikleri ile ilişkilendirilmektedir. Bölgenin yapay kaynaklarını oluşturan konaklama tesisleri, macera aktiviteleri, doğa aktiviteleri ve alışverişle ilgili ifadeler, bölgenin sahip olduğu kaliteli hizmetler sunan konaklama tesislerinin butik, apart, yıldızlı oteller gibi birçok çeşide sahip olması, bölgede yoğun talep gören balon, safari, trekking gibi faaliyetlerin fazla olması ve alışveriş tesisleşmesi ile ilişkilendirilmektedir. Yapay kaynaklarda yer alan su aktiviteleri, spor faaliyetleri, eğlence parkları/tema parkları gibi ifadelerin ortalamalarının düşük olması ise bölgenin ikliminin yanı sıra ilgili alanlarda yeteri düzeyde turistik yatırımların yapılmamış olmasıyla ilişkilendirilebilir.

Destek kaynaklarda, yüksek ortalamaya sahip olan yerel halk, emniyet, güvenlik ve diğer altyapılarla ilgili ifadeler Türkiye genelinde var olan güven ortamı ve Türk halkının bütün yabancılara karşı genel olarak sıcakkanlı olmaları ile ilişkilendirilirken düşük ortalamaya sahip olan gümrük ve vize ile ilgili ifadeler, ilgili yasal süreçlerle ilişkilendirilmektedir. Destinasyon yönetiminde ise bölgedeki çalışanların ve yöneticilerin yetenekleri, bölgeyle ilgili olumlu algılamaların yansıtılması, talebin etkin bir şekilde karşılanması gibi etkenlerden dolayı bütün ifadelerin ortalamanın üzerinde değere sahip olduğu düşünülmektedir. Destinasyon yönetimi ve destinasyonun tercih edilmesinde oldukça önem arz eden bu hususlar, aynı zamanda bölgenin destinasyon rekabetçiliği bakımından da önem arz etmektedir.

Durumsal ve talep koşulların da yer alan ifadelerin ortalama değerleri incelendiğinde, destinasyon yönetiminde yer alan ifadelerle benzer şekilde, genel anlamda bölgenin destinasyon rekabetçiliği bakımından önem arz eden yönleri oluşturdukları görülmektedir. Bu durum özellikle bölgenin sahip olduğu eşsiz güzellikleri ile sanatsal özelliklerinin yoğun olması ve bu unsurların uluslararası düzeyde ilgi çekecek yapıya sahip olması ile ilişkilendirilmektedir.

\section{SONUÇ ve ÖNERILER}

Paydaşlar perspektifine göre gerçekleştirilen Kapadokya Bölgesinin destinasyon rekabetçiliği analizinin sonuçları bir bütün olarak değerlendirildiğinde, bölgenin doğal, kültürel ve tarihi 
kaynaklarının yanı sıra çekici ambiyansı, egzotikliği, ulusal/uluslararası düzeyde sahip olduğu olumlu imajı ve insan hayatının her döneminde ihtiyaç duyulan sağlık, iletişim gibi unsurlar bakımından altyapısı destinasyon rekabetçiliği bakımından sahip olunan güçlü yönleri oluşturmaktadır. Diğer taraftan yapay kaynaklara dayalı su aktiviteleri, spor faaliyetleri, eğlence parkları/tema parkları ve kamuya dayalı bazı hizmetler bakımından bölgenin sınırlı imkânlara sahip olması ise destinasyon rekabetçiliği bakımından sahip olunan zayıf yönleri oluşturmaktadır. Dolayısıyla Kapadokya Bölgesinin rekabetçi pozisyonunun korunması ve güçlendirilmesi için bütün kaynaklarının sürdürülebilir yaklaşım temelinde korunması, konaklama tesisleri ile altyapısının kalite ve çeşitliliğinin devam ettirilmesi, güvenli bir destinasyon algısının ve olumlu imajının desteklenmesi oldukça önem arz etmektedir. Ayrıca yapay kaynaklarda zayıf yön olarak görülen su ve spora dayalı faaliyetler ile kamu/özel sektör çalışanlarının sektör bilgisi/yabancı dil bilgisi gibi unsurların geliştirilmesi ve turizm sektörü ile ilişkili olan ve bölgenin önemli zayıflığı olarak görülen yasal süreçlere yönelik planlanama ve uygulamaların benimsenmesi gerekmektedir.

Kapadokya Bölgesinin destinasyon rekabetçiliğine yönelik elde edilen bulgular ve değerlendirmelerin yanı sıra bu bulgu ve değerlendirmeler doğrultusunda, araştırmanın amacı kapsamında sektör temsilcilerine, politika belirleyicilerine ve gelecekte araştırma yapacak olan araştırmacılara yönelik birtakım öneriler sunulmuştur:

- Alternatif turizm faaliyetlerinin yanı sıra yakın çevrede yer alan şehirlerle bütünleşik tur programlarının hazırlanması ile turistlerin ortalama kalış süreleri ve turistik harcamaları artırılmalıdır.

- Kapadokya Bölgesinin sektörel etkinliğini artıracak destinasyon yönetim örgütü ve uygulamalarına yönelik yasal kolaylıklar sağlanmalıdır.

- Turizm işletmelerinin değişen turist ihtiyaçlarına cevap verebilmeleri için olası değişimlere karşı revizyonu sağlanmalıdır.

- Kapadokya Bölgesinin korunması ve sürdürülebilirliğinin sağlanmasına yönelik yasal süreçler etkin bir şekilde işleyişe konulmalıdır.

- Gümrük ve vizeyle ilgili yasal prosedürleri azaltacak veya ortadan kaldıracak yasal düzenlemeler yapılmalıdır.

- Kapadokya Bölgesinin diğer destinasyonlara kıyasla sahip olduğu fiyat avantajı ucuz bir destinasyon algısı yaratmayacak şekilde korunmalıdır.

- Tüm paydaşların aktif bir şekilde dâhil edildiği karar mekanizmaları oluşturulmalı ve arz/talebin örtüşmesine yönelik faaliyetleri yürütülmelidir.

- Havayolu olmak üzere ulaşım koşulları iyileştirilmelidir.

İlgili alanda araştırma yapacak araştırmacılara, karşılaştırmalı ve bütüncül bir değerlendirme yapabilmek adına hem diğer kültür turizmi destinasyonların hem de alternatif turizm çeşitlerine yönelik destinasyonların rekabetçilik bakımından sahip oldukları güçlü ve zayıf yönlerin belirlenmesi önerilmektedir. Ayrıca araştırma sonuçlarının genellenebilirliğinin artırılması için farklı destinasyonlarda, daha büyük evrenlerde ve farklı yöntem ile tekniklerden yararlanılarak destinasyon rekabetçiliği analizi araştırmalarının yürütülmesi önerilmektedir.

\section{KAYNAKÇA}

Abreu-Novais, M., Ruhanen, L., and Arcodia, C. (2016). Destination Competitiveness: What we know, what we know but shouldn't and What we don't know but should. Current Issues in Tourism, 19(6), 492-512. 
Akın, M. H., Öztürk, Y., ve Karamustafa, K. (2020). Destinasyon Rekabetçilik Analizi: Kapadokya Bölgesi Örneği. Anatolia: Turizm Araştırmaları Dergisi, 31(2), 161-171.

Aktan, C. C. ve Vural, İ. Y. (2004). Rekabet Gücü ve Rekabet Stratejileri. Türkiye İşveren Sendikaları Konfedarasyonu Yayınları.

Andrades, L., and Dimanche, F. (2019). Destination Competitiveness in Russia: Tourism Professionals' Skills and Competences. International Journal of Contemporary Hospitality Management, 31 (2), 910-930.

Armenski, A., Vladimir, M., Nemanja D. and Tamara, J., (2011). Integrated Model of Destinations Competitiveness. Geographica Pannonica. 15(2), 58-69.

Armenski, T., Dwyer, L. and Pavluković, V., (2017). Destination Competitiveness: Public and Private Sector Tourism Management in Serbia. Journal of Travel Research, 57 (3) 384- 398.

Bahar, O. ve Kozak, M. (2012). Turizm ve Rekabet, Ankara: Detay Yayıncilık.

Bajpai, S. and Bajpai, R. (2014). Goodness of Measurement: Reliability and Validity. International Journal of Medical Science and Public Health, 3(2), 112-115.

Bakhshinejad, M., (2014). Porter's Competitive Advantage Model and its Application in Bottled Drinking Water in Iran. Agricultura Tropica Et Subtropica. 47(2), 60-67.

Bayer, M. Z., (1992). Turizme Giriş. İstanbul: İşletme Fakültesi Yayını No: 253.

Bitner, M. J. and Booms, B. H. (1982). Trends in Travel and Tourism Marketing: The Changing Structure of Distribution Channels. Journal of Travel Research, 20 (4), 39-44.

Buhalis, D. (2000). Marketing the Competitive Destination of the Future. Tourism Management, 21, 97-116.

Chen, C. Y., Sok, P. and Sok, K. (2008). Evaluating the Competitiveness of the Tourism Industry in Cambodia: Self-assessment from Professionals. Asia Pacific Journal of Tourism Research, 13(1), 41-66.

Chin, W. L., Haddock-Fraser, J. and Hampton, M. P., (2017). Destination Competitiveness: Evidence from Bali. Current Issues in Tourism, 20(12), 1265-1289.

Croes, R. (2011). Measuring and Explaining Competitiveness in the Context of Small Island Destinations. Journal of Travel Research, 50(4): 431-42.

Crouch, G. I. and Ritchie, J. R. B. (1999). Tourism, Competitiveness and Societal Prosperity. Journal of Business Research, 44, 137-152.

Crouch, G. I. (2011). Destination Competitiveness: An Analysis of Determinant Attributes. Journal of Travel Research. 50 (1), 27-45.

Dahlman, C., (2007). Technology, Globalization, and International Competitiveness: Challenges for Developing Countries. Industrial Development in the 21st Century: Sustainable Development Perspectives, s.29-83.

d'Hauteserre, D. M. (2000). Lessons in Managed Destination Competitiveness: The Case of Foxwoods Casino Resort. Tourism Management, 21, 23-32.

Dupeyras, A., and MacCallum, N. (2013). Indicators for Measuring Competitiveness in Tourism: A Guidance Document. OECD Tourism Papers, 2013/02, OECD Publishing. 
Dwyer, L., Forsyth, P. and Rao, P., (2000). The Price Competitiveness of Travel and Tourism: A Comparison of 19 Destinations. Tourism Management, 21(1), 9-22.

Dwyer, L. and Kim, C., (2003). Destination Competitiveness: Determinants and Indicators. Current Issues in Tourism. 6(5), 369-414.

Dragićević, V., Armenski, T. and Jovićić, D. (2009). Analyses of the Competitiveness of NOVISAD as a Regional Congress Destination. Tourism and Hospitality Management, 15(2), 247-256.

Enright, M. J. and Newton, J. (2004). Tourism Destination Competitiveness: A Quantitative Approach. Tourism Management, 25, 777-788.

Faulkner, B., Opperman, M. and Fredline, E., (1999). Destinations Competitiveness: An Exploratory Examination of South Australia's Core Attractions. Journal of Vacation Marketing, 5(2), 125-139.

Ferreira, J. M. and Estevao, C. M. S. (2009). Regional Competitiveness of a Tourism Cluster: A Conceptual Model Proposal. Tourism \& Management Studies, 5, 37-51.

García Sánchez, A. and Siles López, D. (2015). Tourism Destination Competitiveness and Innovation: The Case of the Spanish Mediterranean Coast. Artal-Tur, A. and Kozak, M (Editors). Destination Competitiveness, the Environment and Sustainability: Challenges and Cases, UK: CABI Publishing.

Goffi, G. and Cucculelli, M., (2012). Attributes of Destinations Competitiveness: The Case of the Italian Destinations of Excellence. Proceedings of The International Conference on Tourism (ICOT, 2012), 23-27 May 2012. Crete, Grece. p.p. 178-189.

Gooroochurn, N. and Sugiyarto, G. (2005). Competitiveness Indicators in the Travel and Tourism Industry. Tourism Economics, 11(1), 25-43.

Gu, T., Ren, P., Jin, M., and Wang, H. (2019). Tourism Destination Competitiveness Evaluation in Sichuan Province Using Topsis Model Based on Information Entropy Weights. Discrete \& Continuous Dynamical Systems-S, 12(4\&5), 771-782.

Gupta, S. and Singh, A., (2019). Measurement Scale of Tourism Destination competitiveness: Supply Side Perspectives. Journal of Indian Management, 16 (1), 105-116.

Hallman, K., Muller, S., Feiler, S., Breuer, C. and Roth, R., (2012). Suppliers' Perception of Destination Competitiveness in a Winter Sport Resort. Tourism Review, 67 (2), 13-21.

Hallman, K., Muller, S. and Feiler, S., (2014). Destination Competitiveness of Winter Sport Resorts in the Alps: How Sport Tourists Perceive Destinations?. Current Issues in Tourism, 17 (4), 327-349.

Hanafiah, M. H. M. and Zulkifly, M. I. (2019). The Evolution of Tourism Destination Competitiveness (TDC) Models. In: Positioning and Branding Tourism Destinations for Global Competitiveness, IGI Global, 2019, 23-48.

Hassan, S. S. (2000). Determinants of Market Competitiveness in an Environmentally Sustainable Tourism Industry. Journal of Travel Research. 38, 239-245.

Heath, E., (2002). Towards a Model to Enhance Africa's Sustainable Tourism Competitiveness. Journal of Public Administration. 37(3.1), 327-353.

http://www.surveysystem.com/sscalc.htm, Erişim: 06 Şubat 2019. 
Luštıcký, M. and Musil, M. (2019). Stakeholders Influence on the Competitıveness Factors of Tourısm Destınatıon. XXII. Mezinárodní Kolokvium o Regionálních Vědách, 12-14 Haziran 2019. Brno. p.p. 470-476.

VIII. Lisansüstü Turizm Araştırmaları Kongresi, 29-30 Nisan 2016. Nevşehir. ss. 172-183.

Karasar, N. (2014). Bilimsel Araştırma Yöntemi (Yirmiyedinci Baskı). Ankara: Nobel Yayınevi.

Khin, E., Daengbuppha, J. and Nonsiri, P. (2014). Destination Competitiveness: A Structural Model for Measuring Attributes Competitiveness of Bagan, Myanmar. International Journal of Business, Economics and Law, 4 (2), 51-59.

Kubickova, M. and Martin, D. (2020). Exploring the Relationship Between Government and Destination Competitiveness: The TALC Model Perspective. Tourism Management, 78 (2020): 104040.

Mangion, M. L., Durbarry, R., and Sinclair, M. T. (2005). Tourism Competitiveness: Price and Quality. Tourism Economics, 11(1), 45-68.

Meng, F. (2006). An Examination of Destination Competitiveness from the Tourists' Perspective: The Relationship between Quality of Tourism Experience and Perceived Destination Competitiveness. Doctor in Philosophy Dissertation Submitted to the Faculty of the Virginia Polytechnic Institute and State University.

Nadalipour, Z., Khoshkhoo, M. H. I., and Eftekhari, A. R. (2019). An Integrated Model of Destination Sustainable Competitiveness. Competitiveness Review: An International Business Journal. 29(4), 314-335.

Nkinda, P. D., Prem, C. C., and Srinivas, M. (2018). Stakeholders' Views on the Determinants of Tourism Competitiveness of Northern Tourist Circuit Nature Based Destinations in Tanzania. Uongozi Journal of Management and Development Dynamics, 28(1), 1-26.

Pansiri, J. (2014). Tourist Motives and Destination Competitiveness: A Gap Analysis Perspective. International Journal of Hospitality \& Tourism Administration, 15, 217-247.

Porter, M.E. (1980). Competitive Strategy: Techniques for Analysing Industry and Competitors, Free Press, New York.

Porter, M. E. (1990). The Competitive Advantage of Nations. New York, NY: The Free Press.

Reisinger, Y., Michael, N. and Hayes, J. P., (2018). Destination Competitiveness from a Tourist Perspective: A Case of the United Arab Emirates. International Journal of Tourism Research, 21, 259279.

Ritchie, J.R.B. and Crouch, G.I. (2003). The Competitive Destination: A Sustainable Tourism Perspective. UK: CABI Publishing.

Scorțe, C., Dragolea, L. and Paschia, L. (2013). Tourism - The Main Component of Hospitality Industry - Its Evolution in Romania. Annales Universitatis Apulensis Series Oeconomica, 15 (2), 703715.

Tsai, H., Song, H. and Wong, K. K. F. (2009). Tourism and Hotel Competitiveness Research, Journal of Travel - Tourism Marketing, 26, 522-546. 
Vujko, A., Petrovic, M. D., Dragosavac, M. and Gajic, T. (2016). Differences and Similarities Among Rural Tourism in Slovenia and Serbia - Perceptions of the Local Tourism Workers. Economics of Agriculture, 4(63), 1459-1469.

Yüzbaşığlu, N., Çelik, P. ve Topsakal, Y., (2016). Antalya Destinasyonunun Turizm Rekabetçiliğinin Belirlenmesine Yönelik Ampirik Bir Çalışma. VIII. Lisansüstü Turizm Araştırmaları Kongresi, 29-30 Nisan 2016. Nevşehir. ss. 172-183.

Zhou, Y., Maumbe, K., Deng, J. and Selin, S. W., (2015). Resource-based Destination Competitiveness Evaluation Using a Hybrid Analytic Hierarchy Process (AHP): The Case Study of West Virginia. Tourism Management Perspectives, 15, 72-80. 